Çukurova Üniversitesi Mühendislik Mimarlık Fakültesi Dergisi, 32(1), ss. 99-108, Mart 2017

Çukurova University Journal of the Faculty of Engineering and Architecture, 32(1), pp. 99-108, March 2017

\title{
Bakır Konsantre Tesislerinde Kontrol Kartlarının ve Çok Boyutlu Ölçekleme Analizinin Uygulanması
}

\author{
Volkan ARSLAN ${ }^{* 1}$ \\ ${ }^{1}$ MTA Genel Müdürlüğü, Orta Anadolu II. Bölge Müdürlüğü, Konya
}

Geliş tarihi: 05.01.2017 Kabul tarihi: 14.03.2017

\section{$\ddot{\mathbf{O} z}$}

Bu çalışmada, Türkiye'deki iki bakır zenginleştirme tesisinde istatistiksel kalite kontrol uygulaması yapılmıştır. Elde edilen bilgilerle üretim sürecinin yeterli olup olmadığını tespit etmek amacıyla proses yeterlilik analizi yapılmıştır. A ve $B$ tesisleri için $C_{p}$ ve $C_{p k}$ indisleri sırası ile $1,42,1,20$ ve 1,50,1,10 bulunmuştur. Bu değerlere göre proseslerin ihtiyaçları karşıladığı tespit edilmiştir. Ayrıca, çok boyutlu ölçekleme (ÇBÖ) analizi ile stress değeri ve korelasyon indeksi değeri tespit edilmiştir. Hesaplamalar sonucunda stress değeri 0,01258 bulunmuş ve bu değer konfigürasyon uzaklıkları ile tahmini uzaklıklar arasında mükemmel bir uyum olduğunu göstermiştir. Korelasyon indeksi değeri $\left(\mathrm{R}^{2}\right) 0,99923$ 'dür. $\mathrm{Bu}$ değer güvenilirlik açısından öklid uzaklık modelinin verileri çok iyi temsil ettiğini göstermektedir. Çok boyutlu ölçekleme analizi sonuçlarının çalışmada kullanılan veri setini yeterli ölçüde yansıttığı görülmektedir.

Anahtar Kelimeler: Bakır konsantre tesisi, Kontrol grafikleri, Proses yeterlilik analizi, Çok boyutlu ölçekleme analizi

\section{The Application of Control Charts and Multidimensional Scaling Analysis in Copper Concentrate Plants}

\begin{abstract}
In this study, statistical quality control application was applied to two copper concentrate plants in Turkey. Process capability analysis was carried out to determine whether there was sufficient of the production process with the information obtained. The $\mathrm{C}_{\mathrm{p}}$ and $\mathrm{C}_{\mathrm{pk}}$ indices for $\mathrm{A}$ and $\mathrm{B}$ plants were 1.42, 1.20 and $1.50,1.10$, respectively. According to these values, it has been determined that the processes meet the needs. Furthermore, stress index value and the correlation value were determined with multidimensional scaling (MDS) analysis. As a result of the calculations, the stress value was founded 0.01258 , indicating that this was a perfect fit between the configuration distances and the estimated distances. The correlation index value $\left(\mathrm{R}^{2}\right)$ was 0.99923 . This value showed that the euclidean distance model represents the data very well in terms of reliability. Multidimensional scaling analysis of the results of the data set used in this study seems to adequately reflect.
\end{abstract}

Keywords: Copper concentrate plant, Control charts, Process capability analysis, Multidimensional scaling analysis

*Sorumlu yazar (Corresponding author): Volkan ARSLAN, volkanarslan76@hotmail.com 


\section{GíRiş}

İstatistiksel kalite kontrolü, bir ürünün en ekonomik ve yararlı bir şekilde üretilmesini sağlamak, önceden belirlenmiş kalite özelliklerine uygunluğunu ve standartlara bağlılı̆̆ını hedef almak, kusurlu ürün üretimini minimize etmek amacıyla istatistik prensip ve tekniklerinin üretimin bütün safhalarında kullanılmasıdır. İstatistiğin bilgisayar ile entegrasyonu sürecinde kullanımı giderek yaygınlaşan bazı programlar mevcuttur. $\mathrm{Bu}$ programların önde gelenlerinden biri de SPSS (Statistical Package for Social Scientists)'dir. İstatistiksel kalite kontrolü yöntemleri içinde en fazla kullanılan ve bilinen araç kontrol grafikleri olup, 1924 yılında Shewhart tarafından üretim kalitesindeki değişimleri araştırmak amacıyla hazırlanmıştır. Özellikle imalat sanayinde yoğun bir şekilde kullanılan kontrol grafiklerinden son yıllarda madencilik alanında da faydalanılmaya başlanmıştır $[1,2]$. Kontrol altında tutulan bir üretim sisteminden toplanan verilerin kalite özellikleri normal bir dağılım gösterir. Normal dağılmış bir eğride verilerin $\% 99,73$ 'ü $\pm 3 \sigma, \quad \% 95,45$ 'i $\pm 2 \sigma \quad$ ve $\% 68,26$ 'sı $\pm 1 \sigma$ aralığında yer alır. Normal dağılım ve kalite kontrol grafikleri ilişkisi Şekil 1'de verilmiştir [3].

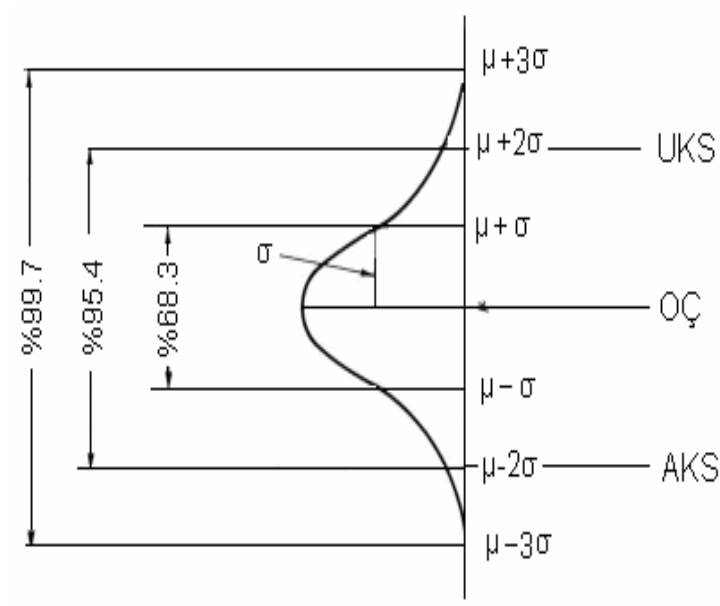

Şekil 1. İstatistiksel kalite kontrolünde normal dağılım eğrisi [3]

İstatistiksel kalite kontrolü çalışmaları 6 aşamaya ayrılmaktadır. Bunlar; prosesin tanımlanması, kontrol edilecek olan karakteristiklerin belirlenmesi, ölçü aletlerinin test edilmesi ve kalibrasyonu, proses yeterlilik analizi, kalite performans analizi ve kalite kontrol grafikleridir. İstatistiksel kalite kontrolü uygulamasının aşamaları Şekil 2'deki gibi gösterilebilir [4,5].

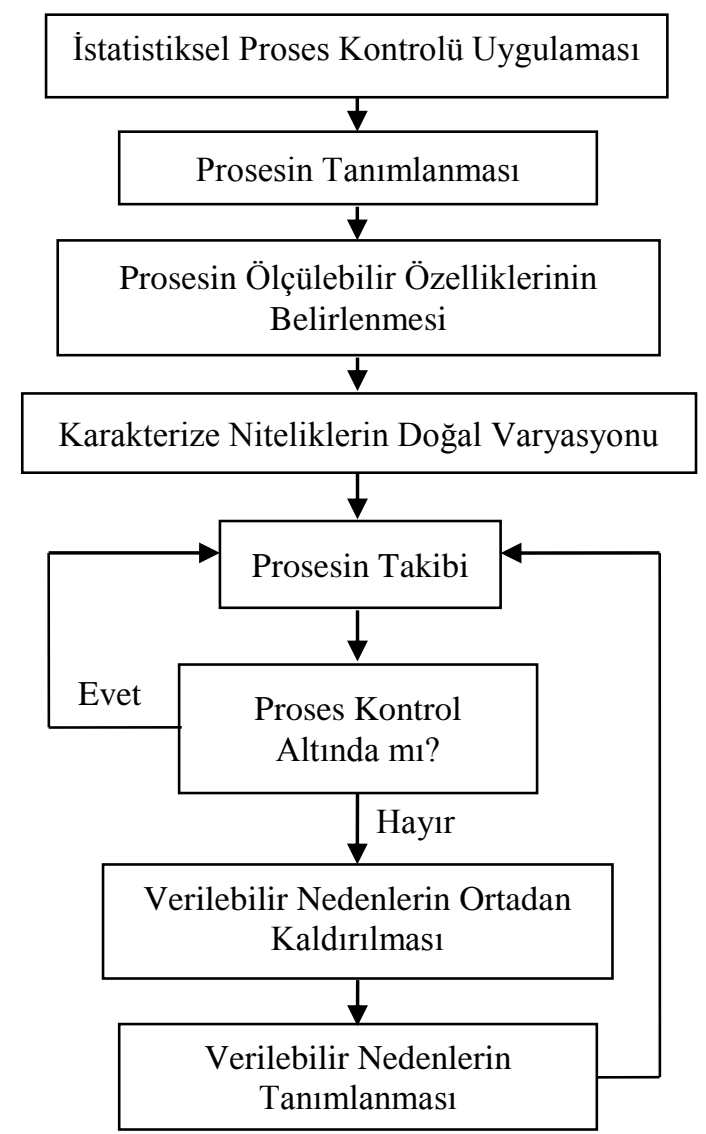

Şekil 2. İstatistiksel kalite kontrolü akış diyagramı [5]

\section{MATERYAL VE YÖNTEM}

\subsection{Değişkenler İçin Kontrol Grafikleri}

Bir üretim sürecinde üretilen her ürünün kalite özelliklerinin değişkenlik göstermesi doğaldır. Kalite ile ilgili işçi, makine ve malzeme gibi özeliklerden kaynaklanan belirlenebilir değișimler daha önemli olup bu etkenlerden kaynaklanan sorunlar olmasi durumunda proses kontrol 
dışındadır ve bu değişmelere yol açan etkenlerin tespit edilip düzeltilmesi kalite kontrolün ana amaçlarındandır. Üretimden belirli ve eşit zaman aralığında alınan örneklerden elde edilen ölçümlerin zamana bağlı değişimlerinin gösterildiği grafiğge kontrol grafiği adı verilir [6]. Merkezi eğilim ve dağılma için kontrol grafikleri "Değişkenler İçin Kontrol Grafikleri" olarak adlandırılır ve bu kontrol grafiklerinin arasında en yaygın biçimde kullanılanları X kontrol grafiği, S kontrol grafiği ve R kontrol grafiğidir. Bir kontrol grafiği esas olarak üç çizgiden oluşur. Bunlar; alt kontrol limiti (AKL), üst kontrol limiti (ÜKL) ve orta değer (OÇ) çizgisidir. Kalite özelliğinin ortalama değeri aynı zamanda hedeflenen değer olarak da ifade edilen orta çizgi ile temsil edilir. $\mathrm{Bu}$ üç temel elemanın hesaplanması için kontrol değişkeni olarak seçilen ve ölçümü yapılarak elde edilen veri tablosundaki veriler alt gruplara bölünürler. Alt grubun numune alma sıklığ1 ise önceden belirlenir ve saatte bir, vardiyada bir, günde 3 gibi belirli bir değere ayarlanır. Her bir alt grup (m) için ortalama ve değişim aralığ hesaplanır. $\mathrm{Bu}$ hesaplamalar için Eşitlik 1'den yararlanılır;

$\overline{\bar{X}}=\frac{\sum_{i=1}^{m} \bar{X}_{i}}{m} ; \bar{R}=\frac{\sum_{i=1}^{m} R_{i}}{m}$

Burada $\bar{X}$ alt grup ortalaması, $\overline{\bar{X}}$ alt grupların ortalamalarının ortalaması, $R_{i}$ alt grup değişim aralığı değeri ve $\bar{R}$ değişim aralıklarının ortalamasıdır. Kontrol sinırlarının belirlenmesinde ise Eşitlik 2-3'den yararlanılır;

$$
\ddot{\mathrm{UKL}}=\overline{\overline{\mathrm{X}}}+\mathrm{A}_{2} \overline{\mathrm{R}} \text { OrtaÇizgi }=\overline{\bar{X}} \quad \mathrm{AKL}=\overline{\overline{\mathrm{X}}}-\mathrm{A}_{2} \overline{\mathrm{R}}
$$

$$
\ddot{\mathrm{UKL}}=\mathrm{D}_{4} \overline{\mathrm{R}} ; \text { OrtaÇizgi }=\overline{\mathrm{R}} ; \mathrm{AKL}=\mathrm{D}_{3} \overline{\mathrm{R}}
$$

Burada, $A_{2}, \quad D_{3}$ ve $D_{4}$ katsay1lar olup örnek sayısına göre değişik değerler almaktadırlar. $\mathrm{Bu}$ hesaplamalar tamamlandiktan sonra grafikler oluşturulup kontrol çizgileri çizilir ve veriler grafikte yerlerine yerleştirilir. Ortaya çıkan grafik yorumlanarak kontrol edilen üretim sistemi hakkında bir değerlendirme yapılır. Yapılacak değişikliklerin sisteme yansımaları da yine grafikler aracılığıyla kontrol edilerek sistemin tepkisi incelenir [3,7-16]. Yukarıdaki formüllerde; $A_{2}, \quad D_{3}, \quad D_{4} \quad$ ve $\quad d_{2}$ doğal toleranslar olarak tanımlanan sabitler olup, alt ve üst kontrol limitlerinin ve proses yeterlilik indislerinin hesaplanmasında Çizelge 1'de verilen bu sabit değerlerden uygun olanlar kullanılmaktadır [2].

Çizelge 1. X-R kontrol kartları için katsayılar [2]

\begin{tabular}{|c|c|c|c|c|}
\hline AGS (n) & $\mathbf{A}_{\mathbf{2}}$ & $\mathbf{D}_{\mathbf{3}}$ & $\mathbf{D}_{\mathbf{4}}$ & $\mathbf{d}_{\mathbf{2}}$ \\
\hline 2 & 1,880 & 0 & 3,267 & 1,128 \\
\hline 3 & 1,023 & 0 & 2,574 & 1,693 \\
\hline 4 & 0,729 & 0 & 2,282 & 2,059 \\
\hline 5 & 0,577 & 0 & 2,115 & 2,326 \\
\hline
\end{tabular}

*AGS: Alt Grup Sayı1

\subsection{Proses Yeterlilik Analizi}

Proses yeterlilik analizinin amac1; proses ortalaması ve standart sapmasını, spesifikasyonlar ile ilişkilendirerek prosesin tüketici isteklerine uygun ürün oluşturup oluşturamadığını değerlendirmektir. İşletmelerin ulaşmak istediği amaç; proses ortalamasının hedef değer üzerinde ve yayılımın spesifikasyonlar içerisinde mümkün olan en küçük değerde oluşmasıdır. Proses yeterliliği, istatistiksel bir ölçüt olup müşteri beklentilerine göre bir sürecin ne kadar değişkenlik gösterdiğini özetler [17].

$\mathrm{Bu}$ aşamada proses yeterlilik analizi, prosese ait ölçülebilir bir kalite karakteristiğinin belirlenen hedef değer, Alt Spesifikasyon Limiti (ASL) ve Üst Spesifikasyon Limiti (ÜSL)'ne göre nasıl bir merkezlenme ve saçılım gösterdiğini inceler. Dikkate alınan parametreler ise $C_{p}$ ve $C_{p k}$ indisleridir. $\mathrm{C}_{\mathrm{p}}$ indisi, şartname limitleri ile proses kontrol limitleri arasındaki ilişkiyi gösterir. $\mathrm{C}_{\mathrm{pk}}$ indisi ise proses ortalamasının hedef değere göre konumunu ve spesifikasyon limitleri arasındaki konumunu gösterir. $\mathrm{C}_{\mathrm{p}}$ ve $\mathrm{C}_{\mathrm{pk}}$ indisleri Eşitlik 4'e göre, standart sapmanın bilinmediği durumlarda ise standart sapma Eşitlik 5'e göre hesaplanır.

$\mathrm{C}_{\mathrm{p}}=\frac{\ddot{\mathrm{U} S L-A S L}}{6 \sigma} ; \mathrm{C}_{\mathrm{pk}}=\min \left(\frac{\ddot{U} S L-\overline{\bar{X}}}{3 \sigma} ; \frac{\overline{\bar{X}}-A S L}{3 \sigma}\right)$

$\sigma=\frac{\overline{\mathrm{R}}}{\mathrm{d}_{2}} ; \quad \sigma=\frac{\overline{\mathrm{s}}}{\mathrm{c}_{4}}$ 
Proses yeterlilik analizinde geçerli olan varsayımlardan biri prosesin istatistiksel olarak kontrol altında olmasıdır. $\mathrm{Bu}$ aşamada yaygın olarak kontrol grafikleri kullanılmaktadır. Kalite karakteristiğinin ölçülebilir değişken olarak tanımlanabildiği durumlarda bu karakteristiğin ortalaması ve değişkenliği sürekli kontrol edilmelidir [14,17-20]. Yeterlilik indisleri hesaplandiktan sonra $C_{p}$ ve $C_{p k}$ değerlerine göre sürecin yeterliliği hakkında karar vermede Çizelge 2'deki veriler kullanılır [21].

Çizelge 2. $\mathrm{C}_{\mathrm{p}}$ ve $\mathrm{C}_{\mathrm{pk}}$ indisinin karar noktaları [21]

\begin{tabular}{|l|l|}
\hline $\mathrm{C}_{\mathrm{p}} \geq 1,33$ & $\begin{array}{l}\text { Proses spesifikasyonları } \\
\text { karşılamaktadır. }\end{array}$ \\
\hline $1<\mathrm{C}_{\mathrm{p}}<1,33$ & $\begin{array}{l}\text { Proses spesifikasyonu } \\
\text { karşılamaz. Proses kontrolü } \\
\text { sürdürülmelidir. }\end{array}$ \\
\hline $\mathrm{C}_{\mathrm{p}} \leq 1$ & $\begin{array}{l}\text { Proses yetersizdir. İyileştirmeler } \\
\text { yapılmalıdır. }\end{array}$ \\
\hline $\mathrm{C}_{\mathrm{pk}} \geq 1$ & $\begin{array}{l}\text { Verilerin tamamı spesifikasyon } \\
\text { sinırları içine düşer. }\end{array}$ \\
\hline $0<\mathrm{C}_{\mathrm{pk}}<1$ & $\begin{array}{l}\text { Proses ortalaması spesifikasyon } \\
\text { sinırlarının içindedir. }\end{array}$ \\
\hline $\mathrm{C}_{\mathrm{pk}} \leq 0$ & $\begin{array}{l}\text { Proses ortalaması spesifikasyon } \\
\text { sinırlarının dışındadır. }\end{array}$ \\
\hline
\end{tabular}

\section{2. Çok Boyutlu Ölçekleme Analizi}

Çok Boyutlu Ölçekleme Analizi (ÇBÖ) n adet gözlem veya örnek arasındaki $p$ değişkene göre belirlenen uzaklıklara dayalı olarak nesnelerin $\mathrm{k}$ boyutlu $(k<p)$ bir uzayda konumlarını saptamayı amaçlayan ve nesneler arasındaki ilişkileri belirleyen bir yöntemdir. ÇBÖ analizinin genel amac1 mümkün olduğu kadar az boyutla, nesnelerin uzaklık değerlerini kullanarak orijinal şekle yakın bir biçimde ortaya koymaktır. Orijinal veriler mümkün olduğunca az boyutlu bir koordinat sistemine yerleştirilmektedir. ÇBÖ analizinde, nesnelerin benzerlikleriyle nesneler arasındaki uzaklıklar karşılaştırılmaktadır. Noktalarla temsil edilen benzer nesneler birbirine daha yakın, farklı nesneler ise birbirine daha uzaktır. ÇBÖ analizinin en önemli kullanım nedenlerinden birisi, kullanıcı karmaşık bir dizi içindeki farklılıkları göstermek istediğinde, kolay bir şekilde görselleştirme sağlamasıdır. ÇBÖ yöntemi uzaklık matrislerinden yararlanarak çözüm yapar. Bu nedenle veri tipine göre uygun uzaklık matrislerini hesaplamak gerekir. En sik kullanılan ölçü Öklid uzaklığıdır ve d boyut için Öklid uzaklığı Eşitlik 6'daki gibi hesaplanır;

$d_{i j}=\sqrt{\sum_{k=1}^{d}\left(X_{i k}-X_{j k}\right)^{2}}$

Burada, $X_{\mathrm{i} 1}, \mathrm{X}_{\mathrm{i} 2}, \mathrm{X}_{\mathrm{i} 3} \ldots \mathrm{X}_{\mathrm{ik}}$ : $\mathrm{X}_{\mathrm{i}}$ vektörünün ve $\mathrm{X}_{\mathrm{j} 1}$, $X_{\mathrm{j} 2}, X_{\mathrm{j} 3} \ldots X_{\mathrm{jk}}: X_{\mathrm{j}}$ vektörünün elemanlarıdır. ÇBÖ analizinde, çok boyutlu ( $p$ boyutlu) gerçek şekil ile indirgenmiş (k-boyutlu) uzayda kestirilen şekil arasındaki farklılığın bir ifadesi olan stress değeri (yani orijinal uzaklıklar ile gösterim uzaklıkları arasındaki uygunluğun ölçüsü) hesaplanır. Metrik olmayan ölçekleme için stress değeri Eşitlik 7'de verilmiştir. Stress değerinin sıfıra yakın olması istenir.

Stress $=\sqrt{\frac{\sum \sum\left(\mathrm{d}_{\mathrm{ij}} \hat{\mathrm{d}}_{\mathrm{ij}}\right)^{2}}{\sum\left(\mathrm{d}_{\mathrm{ij}}\right)^{2}}}$

Kruskal tarafindan 1964 yılında sunulan stress değerine karşılık gelen uygunluk değerleri Çizelge 3'de verilmiştir. ÇBÖ analizinin girdi verilerini ne kadar iyi temsil ettiğine ait korelasyon indeksi değerinin $\mathrm{R}^{2} \geq 0,60$ olması iyi bir uyum olduğunun diğer bir göstergesidir [22-25].

Çizelge 3. Stress değeri ve uygunluk derecesi [25]

\begin{tabular}{|c|c|}
\hline Stress Değeri & Uygunluk Derecesi \\
\hline$\geq 0,20$ & Yetersiz \\
\hline $0,10<0,20$ & Orta \\
\hline $0,05<0,10$ & İyi \\
\hline $0,025<0,05$ & Çok İyi \\
\hline $0,00<0,025$ & Mükemmel \\
\hline
\end{tabular}

\section{SONUÇLAR}

$\mathrm{Bu}$ çalışmada Türkiye'deki önemli iki bakır konsantre tesisinden A tesisi için 01.03.201631.05.2016 ve B tesisi için 01-31.10.2016 tarihleri 
arasında düzenli olarak alınan konsantre bakır tenör değerleri kullanılarak kalite kontrol grafikleri çizilmiş, proses yeterlilik analizi yapılmış ve son olarak çok boyutlu ölçekleme analizi uygulanmıştır. $\mathrm{Bu}$ amaçla her iki tesisten de yukarıda belirtilen dönem boyunca alınan örnekler analiz edilerek değerlendirmeler yapılmış ve analiz değerlerine göre X-R kontrol kartları çizilmiştir (Şekil 3-6). Test edilen zaman aralıklarında konsantre bakır tenör değerlerindeki değişimler incelenmiş ve periyot boyunca gerçekleşen hataların ve sistemdeki sapmaların sebepleri araştırılmış ve çözümler üretilmeye çalışılmıştır. Eşitlik 1-5'e göre $\overline{\bar{X}}, \bar{R}, \mathrm{C}_{\mathrm{p}}, \mathrm{C}_{\mathrm{pk}}, \sigma, \mathrm{AKL}$ ve ÜKL hesaplanmıştır. Tüm hesaplamalarda kullanılan sabit değerler için Çizelge 1'deki değerler dikkate alınmıştır $\quad\left(\mathrm{A}_{2}=1,880, \quad \mathrm{D}_{3}=0, \quad \mathrm{D}_{4}=3,267 \quad\right.$ ve $\left.\mathrm{d}_{2}=1,128\right)$. Ayrıca A işletmesinde $\mathrm{USSL}_{\mathrm{x}}=25$ ve $\mathrm{ASL}_{\mathrm{x}}=13$ ve $\mathrm{B}$ işletmesinde $\mathrm{UHSL}_{\mathrm{x}}=19$ ve $\mathrm{ASL}_{\mathrm{x}}=15,5$ olduğu için buna göre $\mathrm{C}_{\mathrm{p}}$ ve $\mathrm{C}_{\mathrm{pk}}$ değerleri hesaplanmıştır.

\section{A Konsantre Tesisi için;}

$$
\begin{gathered}
\overline{\bar{X}}=\frac{1851,33}{93}=19,91 \\
\mathrm{AKL}_{\mathrm{x}}=27,77-[1,880 \times 1,59]=16,92 \\
\ddot{U K L}_{\mathrm{x}}=27,77+[1,880 \times 1,59]=22,90 \\
\overline{\mathrm{R}}=\frac{147,85}{93}=1,59 \\
\mathrm{AKL}_{\mathrm{R}}=0 \times 1,59=0 \\
\ddot{\mathrm{UKL}}_{\mathrm{R}}=3,267 \times 1,59=5,19 \\
\sigma=\frac{1,59}{1,128}=1,41
\end{gathered}
$$

A işletmesinden alınan konsantre bakır tenör değeri verilerine göre $\ddot{U S L}_{x}=25$ ve $\mathrm{ASL}_{\mathrm{x}}=13$ olduğu belirlenmiş ve buna istinaden $C_{p}$ ve $C_{p k}$ değerleri hesaplanmıştır.

$$
\begin{gathered}
\mathrm{C}_{\mathrm{p}}=\frac{25-13}{6 \times 1,41}=\frac{12}{8,46}=1,42 \\
\mathrm{C}_{\mathrm{pk}}=\frac{25-19,91}{3 \times 1,41}=\frac{5,09}{4,23}=1,20
\end{gathered}
$$

\section{B Konsantre Tesisi için;}

$$
\begin{gathered}
\overline{\bar{X}}=\frac{549,36}{31}=17,72 \\
\mathrm{AKL}_{\mathrm{x}}=17,72-[1,880 \times 0,44]=16,90 \\
\ddot{\mathrm{UKL}}_{\mathrm{x}}=17,72+[1,880 \times 0,44]=18,54 \\
\overline{\mathrm{R}}=\frac{13,49}{31}=0,44 \\
\mathrm{AKL}_{\mathrm{R}}=0 \times 0,44=0 \\
\ddot{\mathrm{UKL}}_{\mathrm{R}}=3,267 \times 0,44=1,44 \\
\sigma=\frac{0,44}{1,128}=0,39
\end{gathered}
$$

B işletmesinden alınan konsantre bakır tenör değeri verilerine göre $\mathrm{USL}_{x}=19$ ve $\mathrm{ASL}_{\mathrm{x}}=15,5$ olduğu tespit edilmiş ve buna istinaden $C_{p}$ ve $C_{p k}$ değerleri hesaplanmıştır.

$$
\begin{aligned}
\mathrm{C}_{\mathrm{p}} & =\frac{19-15,5}{6 \times 0,39}=\frac{3,5}{2,34}=1,50 \\
\mathrm{C}_{\mathrm{pk}} & =\frac{19-17,72}{3 \times 0,39}=\frac{1,28}{1,17}=1,10
\end{aligned}
$$

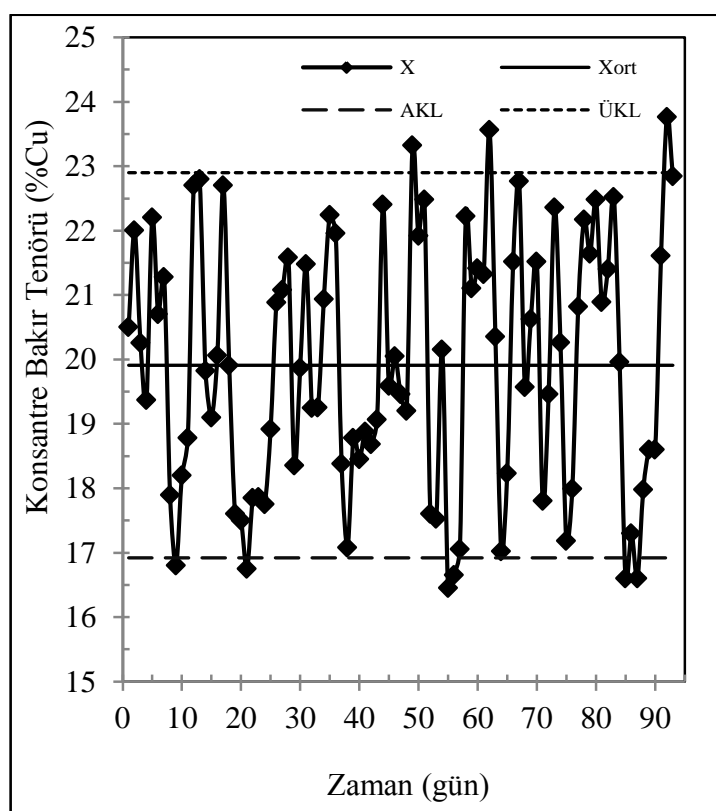

Şekil 3. A Konsantre tesisi bakır tenörü değerleri için X kontrol kartı 


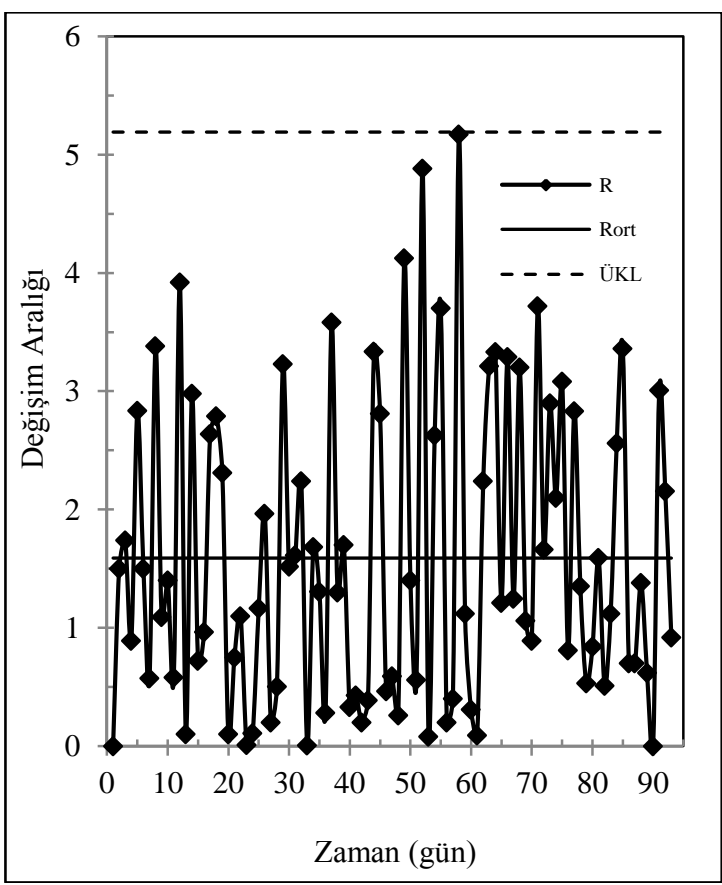

Şekil 4. A Konsantre tesisi bakır tenörü değerleri için R kontrol kartı

Şekil 3-4 incelendiğinde, A konsantre tesisinden alınan verilerinde çok fazla alt ve üst sınır değerlerinden sapmalar gözlenmemiştir. Ancak bakır tenör değerleri alt ve üst kontrol limit değerlerine çok yakın seyretmektedir. Bu durum prosesin sürekli takip edilmesi gerekliliğini göstermektedir. $\mathrm{Bu}$ düzensizlikler test sürecindeki prosese beslenen hammadde kalitesindeki değişkenliklerden, iklimsel şartlardan, işçilikten kaynaklanan nedenlerden veya laboratuardaki analiz cihazlarının kalibrasyon hatalarından kaynaklı olabileceği düşünülmektedir. $\mathrm{Bu}$ düzensizliklerin stabil hale getirilebilmesi için yukarıda bahsedilen nedenlerden kaynaklı olabilecek hataların minimize edilmesi ve küçük düzenlemeler yapılması gerekmektedir. Bu amaçla işletme yetkilileri ile yapılan görüşmeler sonucunda işçilik hatalarından ve cihazların kalibrasyonundan kaynaklı hataların minimize edilmesi için işçilerin eğitim aralıkları sıklaştırılması ve cihazların 2-3 ay aralığında kalibre edilmesi tavsiye edilmiştir. Ancak diğer düzensizlikler için proses tolere edilebilir sınırlar içerisindedir.

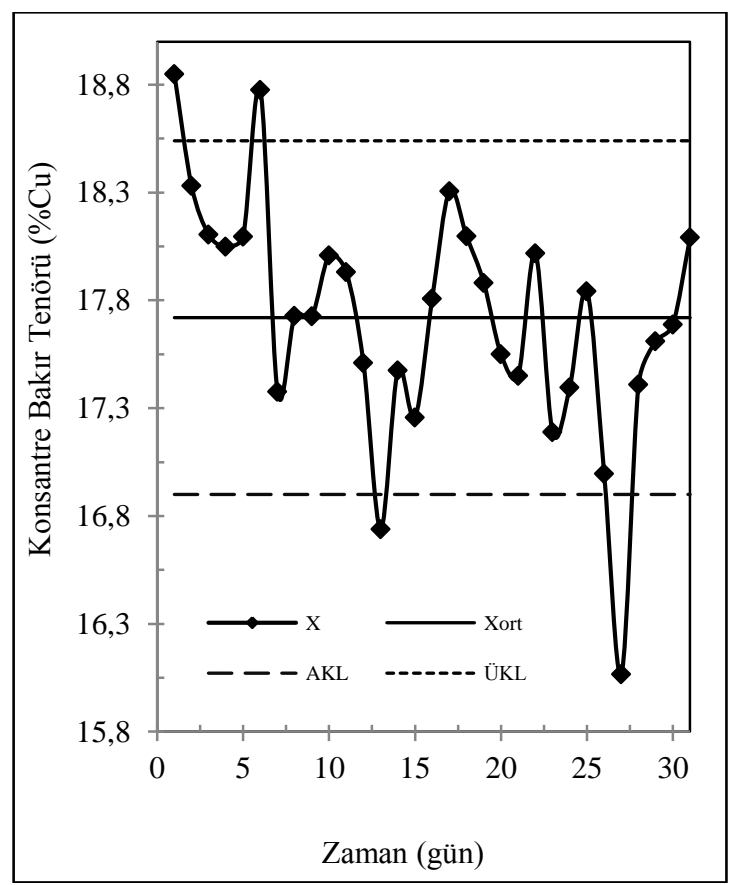

Şekil 5. B Konsantre tesisi bakır tenörü değerleri için X kontrol kartı

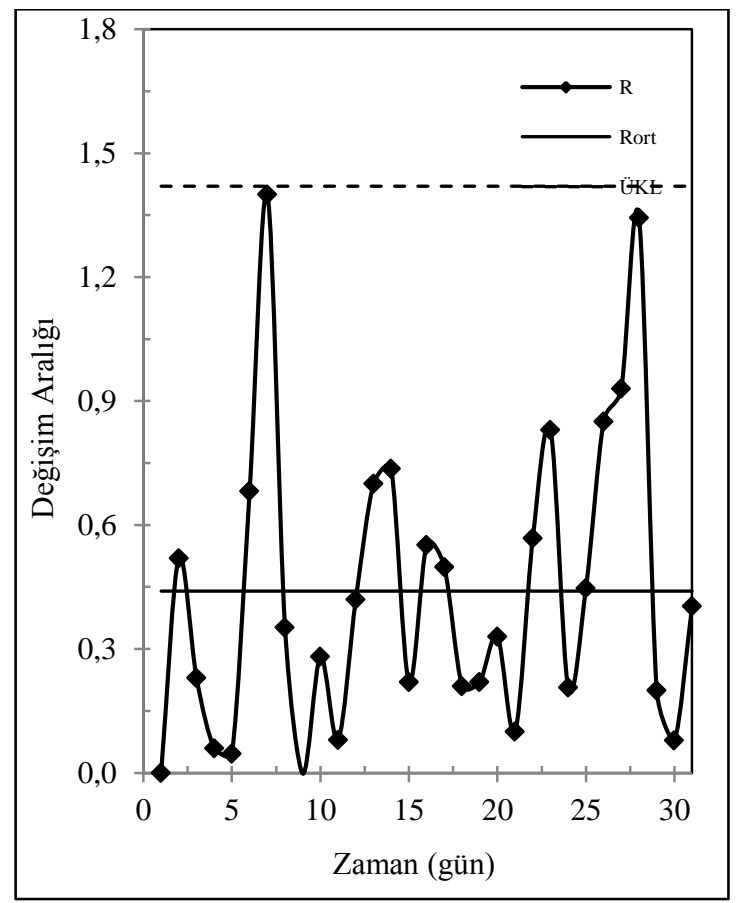

Şekil 6. B Konsantre tesisi bakır tenörü değerleri için R kontrol kartı 
Şekil 5 ve 6 incelendiğinde ise B konsantre tesisinden elde edilen verilerin nispeten daha stabil olduğu gözlenmiştir. Ancak özellikle 1., 6., 13. ve 27. günlerdeki verilerde ani düzensizlikler görülmektedir. $\mathrm{Bu}$ günlerdeki ani sapmalar o günlerde numune alımındaki hatalardan, harmanlamadan kaynaklı hatalardan, işçilikten kaynaklı hatalardan veya laboratuardaki analiz cihazlarının kalibrasyon hatalarından kaynaklı olma ihtimali kuvvetle muhtemeldir. Ancak bu sapmalar proses için tolere edilebilir sınırlar içerisindedir ve sistemde herhangi bir düzenlemeye gerek duyulmamaktadır. A ve B tesislerinden alınan veriler ile yapilan proses yeterlilik analizleri sonuçlarına göre her iki tesis için de $\mathrm{C}_{\mathrm{p}}>1,33$ ve $\mathrm{C}_{\mathrm{pk}}>1$ olduğundan dolayı Çizelge 2'ye göre prosesler yeterli düzeydedir ve prosesler spesifikasyonları karşılamaktadır. Ayrıca her iki proses için de verilerin tamamı spesifikasyon sınırları içine düşmektedir. Son olarak, bu çalışmada bakır konsantre tesislerinin verilerine Çok Boyutlu Ölçekleme (ÇBÖ) analizi de uygulanmıştır. Elde edilen sonuçların, mevcut veri setini yeterli ölçüde yansıtıp yansıtmadığını gösteren stress değerleri incelenerek bu değerin $\mathrm{k}=2$ boyut için daha yüksek olduğu görülmüştür. $\mathrm{Bu}$ nedenle 2 boyutlu ÇBÖ analizi sonuçları verilmiş ve bu sonuçlara ilişkin yorumlar yapılmıştır. Görsel açıdan daha belirgin olmasından dolayı her bir değerin birbirlerine göre konumları öklid uzaklık modeline ilişkin iki boyutlu grafikte gösterilmiştir (Şekil 7).

Yapılan hesaplamalar sonucunda stress değeri 0,01258 olarak bulunmuştur. Çizelge 3'e göre tespit edilen stress değerinin konfigürasyon uzaklıkları ile tahmini uzaklıklar arasında mükemmel düzeyde bir uyum bulunduğunu göstermektedir. Diğer bir deyişle elde edilen sonuçların çalışmada kullanılan veri setini yeterli ölçüde yansıttığı görülmektedir. Ayrıca korelasyon indeksi değeri $\mathrm{R}^{2}=0,99923$ olarak tespit edilmiştir. $\mathrm{Bu}$ değer güvenilirlik açısından öklid uzaklık modelinin verileri çok iyi bir şekilde temsil ettiğini göstermektedir. Gözlemsel uzaklıklar (distances) ile farklılıkların (disparities) dağılımını gösteren Serpilme Diyagramı Şekil 8'de verilmiştir. Buna göre uzaklıklar ile farklılıklar arasında doğrusal bir ilişki bulunmaktadır. $\mathrm{Bu}$ durum, tahmini uzaklıkların gerçek değerlerle uyumlu olduğunu ve doğrusal model ile uygun çözümün elde edilebileceğini göstermektedir.

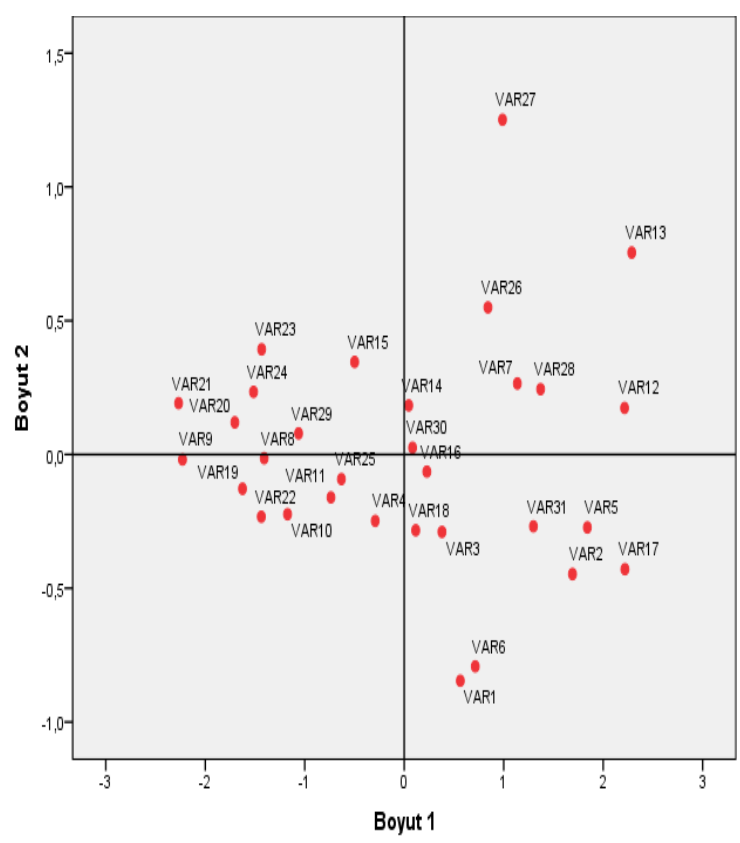

Şekil 7. Bakır konsantre tenör verilerinin 2 boyutlu konumlandirılması

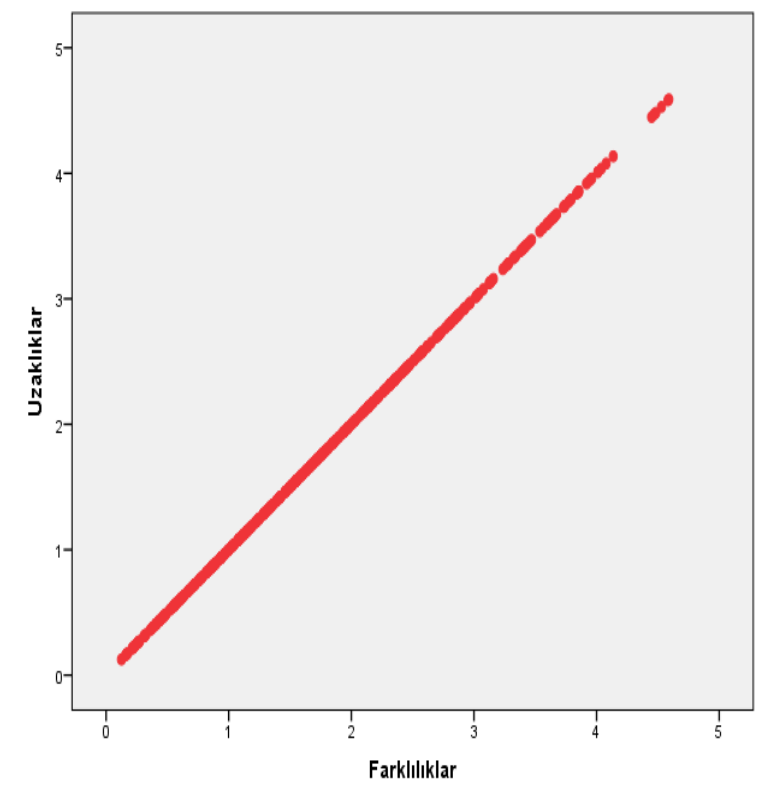

Şekil 8. Öklid uzaklık modeli doğrusal serpilme diyagramı 


\section{4. ÖNERILER VE TARTIŞMA}

Bu çalışmada; Türkiye'deki iki bakır konsantre tesisine SPSS-21 istatistik programı yardımıla istatistiksel kalite kontrol uygulaması, proses yeterlilik analizi ve çok boyutlu ölçekleme analizi uygulanmıştır. Yapılan istatistiksel çalışmalar 1şı̆̆ında aşağıdaki sonuçlara ulaşılmıştır.

- Konsantre bakır tenörü değerleri için çizilen kontrol kartlarına göre A tesisindeki veriler alt ve üst sınır değerlere çok yakın olmakla birlikte genellikle sınır değerler içerisinde kalmış veya çok az sınır değerleri aşmıştır. Bu yüzden $\mathrm{A}$ tesisi düzenli olarak takip edilmeli ve tespit edilen anormal değişimler sürekli not edilmelidir. A tesisi yetkilileri ile yapılan görüşmeler neticesinde bu dalgalanmaların daha çok iklimsel şartlardan, işçilik hatalarından ve cihazların kalibrasyon sorunlarından kaynaklandığı tespit edilmiş ve bu amaçla yapılan görüşmeler sonucunda işçilik hatalarından ve cihazların kalibrasyonundan kaynaklı hataların minimize edilmesi için işçilerin eğitim aralıklarının sıklaştırılması ve cihazların 2-3 ay aralığında kalibre edilmesi tavsiye edilmiştir.

- B tesisi için çizilen X-R kontrol kartları incelendiğinde ise çok fazla alt ve üst sınır değerlerden sapmaların olmadığ 1 ve test dönemi boyunca yalnızca 3 gün (1., 6., 27. günlerde) sınır değerlerin dişına çıktığı görülmüştür. $\mathrm{Bu}$ durum genel tablo içerisinde tolere edilebilir.

- Proses yeterlilik analizlerinde ise $A$ tesisi için $C_{p}$ ve $C_{p k}$ değerleri sırası ile 1,42 ve 1,20 bulunmuştur Aynı şekilde $\mathrm{B}$ tesisi içinse bu değerler 1,50 ve 1,10 olarak belirlenmiştir. $\mathrm{Bu}$ sonuçlara ve Çizelge 2'deki verilere göre $\mathrm{C}_{\mathrm{p}}>1,33$ ve $\mathrm{C}_{\mathrm{pk}}>1$ olduğundan dolayı işletme müşterilerin isteklerini karş1layabilecek kalitede üretim yapmaktadır, spesifikasyonları karşılamaktadır ve verilerin tamamına yakını spesifikasyon sınırları içine düşmektedir.

- Son olarak yapılan çok boyutlu ölçekleme analizine göre stress değeri 0,01258 bulunmuş ve bu değer konfigürasyon uzaklıkları ile tahmini uzaklıklar arasında mükemmel bir uyum olduğunu göstermiştir. Ayrıca korelasyon indeksi değeri $\left(\mathrm{R}^{2}\right)$ de 0,99923 olarak tespit edilmiştir. Bu değer güvenilirlik açısından öklid uzaklık modelinin verileri çok iyi temsil ettiğini göstermektedir.

\section{KAYNAKLAR}

1. Akın, B., Öztürk, E., 2005. İstatistik Proses Kontrol Tekniklerinin Bilgisayar Ortamında Uygulanmas1, 7. Ulusal Ekonometri ve İstatistik Sempozyumu, 2-15, İstanbul.

2. Elevli S., Bedhioğlu S., 2006. İstatistiksel Proses Kontrolü Teknikleri ile Kömür Kalitesindeki Değişkenliğin Belirlenmesi, Madencilik Dergisi, 45, 3, 19-26.

3. Akkoyun, Ö., 2006. Kalite Kontrol Grafikleri Oluşturmak için Bir Bilgisayar Yazılımının Geliştirilmesi ve Mermer Sektöründe Denenmesi, Geosound Yerbilimleri Dergisi, Say1: 48-49 ISSN 1019-1003.

4. Şahin O., 2013. İstatiksel Proses Kontrolünde Kontrol Grafiklerinin Kullanımı ve Tekstil Sanayinde Bir Uygulama, Dicle Üniversitesi Sosyal Bilimler Enstitüsü Dergisi, 10, 53-75.

5. Madanhirea, I., Mbohwab, C., 2016. Application of Statistical Process Control (SPC) in Manufacturing Industry in a Developing Country, Procedia CIRP 40, 580-583.

6. Bircan, H., Özcan, S., 2003. Excel Uygulamalı Kalite Kontrol, Yarg1 Yayınevi, 375 syf., Ankara.

7. Devor R. E., Chang T., Sutherland J. W., 1992. Statistical Quality Design and Control, Macmillan Publishing Company, NewYork, USA.

8. Juran J. M., Gryna F. M., 1993. Quality Planning and Analysis, $3^{\text {rd }}$ Edition, McGrawHill Company, 383-396, USA.

9. Ankara H., Bilir K., 1995. Kriblaj Tesisinde Kalite Denetimi, Madencilikte Bilgisayar Uygulamaları Sempozyumu, 235-240, İzmir.

10. Akın B., 1996. İşletmelerde İstatistik Proses Kontrol, Bilim Teknik Yayınevi, 150 syf., İstanbul.

11. Grant E.L., Leavenworth R.S., 1996. Statistical Quality Control, $7^{\text {th }}$ Edition, McGraw-Hill Company, 35-116, USA. 
12. Ertuğrul, İ., 2004. Toplam Kalite Kontrol ve Teknikleri, Hünkar Yayınevi, 209-258, İstanbul.

13. Burr J.T., 2005. Elementary Statistical Quality Control, $2^{\text {nd }}$ Edition, Marcel Dekker CRC Press, 480 p., New York, USA.

14. Montgomery D. C., 2007. Introduction to Statistical Quality Control, $4^{\text {th }}$ Edition., John Wiley and Sons Inc., 818 p., New Jersey, USA.

15. Ryan T.P., 2011. Statistical Methods for Quality Improvement, $3^{\text {rd }}$ Edition, John Wiley and Sons Inc., 657, New Jersey, USA.

16. Arslan V., Bayat, O., 2012. Çukurova Bölgesindeki Kömür Briketleme Fabrikalarına İstatistiksel Kalite Kontrol Uygulamas1, Türkiye 18. Kömür Kongresi, 111-122, Zonguldak.

17.Zeyveli M., Selalmaz E., 2008. İstatistiksel Proses Kontrol Tekniklerinin Zincir İmalat1 Yapan Bir İşletmede Uygulanmas1, Doğu Anadolu Bölgesi Araştırmaları, 36-45, Elazı̆̆.

18. Kolark W. J., 1995. Creating Quality, Industrial Engineering Series, McGraw-Hill Company, 925 p., USA.

19. Vapur H., Bayat O., Akyol F., 2005. Eti Gümüș A.Ş. Liç Prosesinde İstatistiksel Proses Kontrolü Uygulamas1, 19. Uluslararas1 Madencilik Kongresi, 347-356, İzmir.

20. Aydın Ö., Pakdil F., Aydın Ö., 2010. Kömür Kalorisi Değişkenliğinin Azaltılmasında Proses Yeterlilik Analizi, Osmangazi Üniversitesi Mühendislik Mimarlık Fakültesi Dergisi, 23, 2, 1-17, Eskişehir.

21. Işı̆̆ıçok E., 2012. Toplam Kalite Yönetimine Bakış Açısıyla İstatistiksel Kalite Kontrol,2. Baskı, Ezgi Yayınevi, 412, Bursa.

22. Doğan, İ., 2003. Kuzularda Büyümenin Çok Boyutlu Ölçekleme Yöntemi ile Değerlendirilmesi, Uludağ Üniversitesi, Veterinerlik Fakültesi Dergisi, 22, 1, 33-37, Bursa.

23. Tüzüntürk, S., 2009. Çok Boyutlu Ölçekleme Analizi: Suç İstatistikleri Üzerine Bir Uygulama, Uludağ Üniversitesi, İktisadi ve İdari Bilimler Fakültesi Dergisi, 28, 2, 71-91, Bursa.

24. Bülbül, S., Köse, A., 2010. Türkiye'de Bölgelerarası İç Göç Hareketlerinin Çok Boyutlu Ölçekleme Yöntemi ile İncelenmesi,
İstanbul Üniversitesi İşletme Fakültesi Dergisi, 39, 1, 75-94, İstanbul.

25. Çelik, Ş., 2015. Çok Boyutlu Ölçekleme Analizi ile Hayvancılık Açısından Türkiye'de İllerin Sinıflandırılması, Erciyes Üniversitesi Fen Bilimleri Enstitüsü Dergisi, 31, 4, 159-164, Kayseri. 
